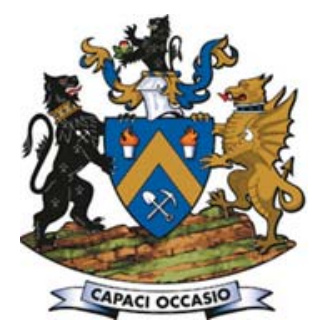

\title{
Natural tourmaline as an efficient alternative to ceramic-type material for plasma spraying
}

\author{
by P. Ctibor*, B. Nevrlá*†, Z. Pala*, and L. Vrtiška*
}

\section{Synopsis}

Expensive synthetic materials with top-quality properties are often used to prepare coatings deposited by plasma spraying. Such high quality is not needed for a variety of end-user applications. We selected natural mineral tourmaline as an inexpensive alternative material and sprayed it successfully, forming a ceramic-like coating. The experimental powder for spraying was as-mined tourmaline schorl, and was only crushed and sieved to the appropriate size for plasma spraying with a hybrid water-argon stabilized plasma torch (WSP-H). Deposits on metallic and ceramic substrates, as well as self-supporting plates and samples annealed in air at $1000^{\circ} \mathrm{C}$, were further studied by optical microscopy, X-ray diffraction, thermal and mechanical analysis, and optical reflectance tests. The results showed that the coatings are highly porous ( $44 \pm 8 \%$ in the most extreme case) and partly amorphous tourmaline is always formed by plasma spraying. The crystallinity depended on the process parameters. During subsequent annealing, tourmaline decomposed to a mullite-like phase and haematite; this process was accompanied by a microhardness increase, in spite of retained microstructure defects. Plasma spraying of a material with structurally bonded water and with incongruent melting, where both factors are considered as major disadvantages, was demonstrated.

Keywords

plasma spraying, tourmaline, crystallinity, annealing.
Liu et al. (2008) deposited a tourmaline film about $170 \mathrm{~nm}$ thick on glass by ion beam. However, tourmaline had never been processed by plasma spray before this work. Processing of materials that melt incongruently (in the case of tourmaline this is it mainly because of the $\mathrm{OH}$ group in its structure) is a challenge for the plasma spray technique with its typical rapid quenching. Due to the processing parameters used, rather than production of piezoelectric parts, we targeted our spray campaign onto environmental barriers or ultra-low weight ceramic parts.

Plasma spraying offers deposition of silicate glasses on many kinds of substrates without thermal damage to the substrate (Cojocaru et al., 2013; Salimijazi et al., 2012; Wang et al., 2012). Various silicates already have well-established applications but these single-phase ceramics require sintering at a high temperature, which is sometimes a serious drawback. Since silicates are reliable, inexpensive, and easy to process (Zhang et al., 2014), investigation of multi-phase silicates is also useful because these include natural geomaterials. Moreover, plasma spraying can offer selective evaporation of some unwanted admixtures (impurities) (Ctibor, Brožek, and Hofman, 2003; Rykalin and Kudinov, 1976). In our material the $\mathrm{OH}$ group and partly also $\mathrm{F}$ and $\mathrm{Na}$ tended to preferentially evaporate. Tourmaline is studied as a candidate material for possible replacement of high-melting-point synthetic silicates, since tourmaline is an inexpensive geomaterial with a low melting point.

* Institute of Plasma Physics, ASCR, Czech Republic.

+ Department of Materials Engineering, Faculty of Mechanical Engineering, Czech Technical University in Prague, Czech Republic.

₹ Department of Mineralogy and Petrology, National Museum, Horni Počernice.

(C) The Southern African Institute of Mining and Metallurgy, 2018. ISSN 2225-6253. Paper received Aug. 2017; revised paper received Feb. 2018. 


\section{Natural tourmaline as an efficient alternative to ceramic-type material for plasma spraying}

Also, synthetic ceramic materials such as $\mathrm{Pb}\left(\mathrm{Mg}_{1 / 3} \mathrm{Nb}_{2 / 3}\right) \mathrm{O}_{3}-\mathrm{Pb}\left(\mathrm{Zr}_{0.48} \mathrm{Ti}_{0.52}\right) \mathrm{O}_{3}$ exhibit incongruent melting, which makes plasma spraying difficult (Liu et al., 2017).

The novelty of our research was to spray material with chemically bound water in its structure and exhibiting incongruent melting. Plasma spraying of a material combining both these obstacles has, according our knowledge, not been previously reported. Since the bound water is responsible for the incongruent melting, the key factor is to find spay parameters for melting maximum amounts of the powder mass.

\section{Experimental}

\section{Process requirements}

The samples were produced using a high feed rate plasma spray system with a hybrid stabilization by two media water and argon WSP-H (IPP, Prague, Czech Republic) (Jenista et al., 2011). This system operates at arc power up to $160 \mathrm{~kW}$ and can process a large amount of material per hour. Natural as-mined tourmaline was crushed and sieved to obtain the feedstock powder for spraying. This powder had a size distribution of $63-125 \mu \mathrm{m}$, which is required by the features of the WSP-H system plasma jet. Plasma spray parameters were adjusted using observation of single splats sprayed on non-treated surfaces of laboratory glass.

\section{Coating preparation}

Stainless steel coupons, as well as ceramic tiles, were used as substrates for coating. The substrates were grit-blasted before spraying. The substrates were preheated to $300^{\circ} \mathrm{C}$ just before spraying. The preheated substrate provides a better platform for the coating crystallization and reduces the amount of amorphous phase formed in the coating due to the slightly prolonged quenching time of individual droplets (Fauchais et al., 2004). Spreading of splats is also enhanced (Fauchais et al., 2004). The powder was fed in by compressed air through two injectors. The thickness of the deposited coating was from 0.5 to $2 \mathrm{~mm}$. To form selfsupporting plates (SSP), several deposits were later removed from the substrate by thermal cycling at approximately $-170^{\circ} \mathrm{C}$ to $+100^{\circ} \mathrm{C}$.

\section{Thermal post-treatment}

Annealing of the as-sprayed SSP and some coatings on ceramic tiles was carried out in air in a laboratory furnace using two regimes. In both regimes, the temperature was set to $1000^{\circ} \mathrm{C}$, and heating as well as cooling were done at a rate of $7 \mathrm{~K} / \mathrm{min}$. Dwell time was 30 minutes in the first case and 8 hours in the other case. Annealing temperature was chosen on the basis of the thermal analysis results so as to be above the tourmaline transformation temperature. The short and long dwell times were chosen in order to observe how much the annealing process changes the microstructure, crystallinity, and mechanical aspects of tourmaline.

\section{Sample characterization}

\section{Phase composition}

Powder samples of the feedstock and sprayed SSP, as well as the coatings, were analysed by X-ray diffraction. The aim was to obtain information about the crystalline phases, their amounts, and degree of crystallinity. All samples were measured in the same manner on Bruker D8 Advance diffractometer in Bragg-Brentano geometry with $\mathrm{Cu}-\mathrm{K} \alpha$ radiation and a 1D LynxEye detector. Precise alignment of the sample surfaces was done by laser. Topas software version 4.2 was used for quantitative Rietveld analysis. The amorphous material was assumed to be of the same chemical composition, so the crystallinity was computed from integral intensities of crystalline phases and amorphous haloes only.

\section{Thermal analysis}

Differential thermal analysis (DTA) curves were obtained by simultaneous thermal analyser (TG-DTA, Bähr, Germany) using a B-type thermocouple. A heating rate of $10 \mathrm{~K} / \mathrm{min}$ was applied up to $1100^{\circ} \mathrm{C}$ in a dynamic argon atmosphere (flow rate $5 \mathrm{l} / \mathrm{h}$ ). The weight of the feedstock powder was $30 \mathrm{mg}$ and was measured in an alumina crucible. The results were corrected by blank subtraction.

\section{Microstructure}

Samples were sectioned using a diamond cutting blade and cross-sections were mounted in a low-viscosity resin. Metallographically polished cross-sections were prepared from as-deposited SSP samples. Grinding and polishing of the samples was carried out using an automatic polishing system Tegramin-25 (Struers, Denmark). Cross-sections of the samples were observed under a light microscope Neophot 32 (Carl Zeiss SMT, Germany).

\section{Porosity, microhardness, and roughness}

Porosity was studied by optical microscopy on polished crosssections. Micrographs were taken with a CCD camera and processed using image analysis (IA) software (Lucia G, Laboratory Imaging, Czech Republic). Porosity levels were determined by IA based on differentiating between porosity and bulk coating by the grey levels. Ten images of microstructures taken from various areas of the cross-section for each sample were analysed. In addition to a simple quantification of porosity, other porosity features of selected coatings were also examined. Density was determined by Archimedes' principle (water immersion).

Vickers microhardness of the coatings was measured on polished cross-sections using an optical microscope equipped with a Hanemann head and Vickers indenter using a $1 \mathrm{~N}$ load applied over 15 seconds. The mean value of the microhardness was calculated as an average from 20 indentations.

Surface roughness was determined by a contact method using the Surtronic 3P (Taylor-Hobson, UK) apparatus on a length of $13 \mathrm{~mm}$ repeated five times on various parallel tracks.

\section{Wear resistance}

The slurry abrasion response (SAR) of coatings was measured with respect to ASTM G 75-95 (ASTM, 1995). The SAR test is based on measuring the mass loss rate of a standard-shaped block $(7.5 \mathrm{~mm} \times 12 \mathrm{~mm} \times 25 \mathrm{~mm})$ immersed in a slurry. The test was run for more than $9000 \mathrm{~m}$ in four equal increments, with the mass loss being 


\section{Natural tourmaline as an efficient alternative to ceramic-type material for plasma spraying}

measured at the end of each increment. The applied force was $22 \mathrm{~N}$ per specimen. After each run the specimens were ultrasonically cleaned and weighed. The slurry consisted of $150 \mathrm{~g}$ of water and $150 \mathrm{~g}$ of alumina powder with a particle size of $40-50 \mu \mathrm{m}$. Accuracy of the measurement was approximately $\pm 5 \%$. The results were expressed as inverse wear rate (IWR), which represents the length of path necessary to remove one cubic millimeter of material. The higher the IWR, the better the wear resistance.

\section{Reflectance}

Reflectance measurement in this work was performed using an ultraviolet/visible/near-infrared (UV/Vis/NIR) spectrophotometer (Shimadzu, Japan). Prior to the measurement a calibration process was conducted using a $\mathrm{BaSO}_{4}$ reference mirror in order to minimize the error from the environment. The accuracy guaranteed by the manufacturer is $\pm 0.3 \mathrm{~nm}$, independent of actual wavelength, and the uncertainty of measurement was less than $0.2 \%$. The wavelength of incident light used for the reflectance measurement was in a range from $250 \mathrm{~nm}$ to $2000 \mathrm{~nm}$ and the measured area was about $2 \mathrm{~cm}^{2}$.

\section{Results and discussion}

The WSP-H system allows adjustment of the feeding distance (FD), which is the axial position of the powder injector with respect to the plasma nozzle. Figure 1 depicts single splats sprayed from four different spray distances at a fixed feeding distance of $40 \mathrm{~mm}$. For the shortest spray distance (SD), a plasma nozzle to substrate stand-off of $300 \mathrm{~mm}$, the splats were fragmented, which indicates impact at too high a temperature and at an unacceptably high velocity. When the SD was set to $400 \mathrm{~mm}$ or $450 \mathrm{~mm}$, the splats frequently bounced off (the central part of the splat is absent or damaged) because of low impact temperature and velocity. At a medium SD of $350 \mathrm{~mm}$ the splats were surrounded by long 'fingers', but only in this case was the central part completely solid. This indicated that the most suitable conditions for coating build-up are at SD $350 \mathrm{~mm}$.

However, the characteristics of single splats is not the only consideration for process optimization, because the cooling regime is not easily transferable to a different substrate material. Free-flight particles (FFP, i.e. particles passing through the plasma but not impacting the glass substrate) were observed also.

Figure 2 shows the appearance of FFP from two markedly different FDs. At the short FD $(40 \mathrm{~mm})$ the particles were well spheroidized, which signifies proper melting. At the long FD $(80 \mathrm{~mm})$ a larger amount of less well spheroidized particles was present. The incongruent melting was responsible for the dramatic difference among various particles collected at FD $40 \mathrm{~mm}$ (Figure 3). Many of them were foam-like with internal porosity. The mixture of wholly molten and partly molten particles, several of which were foam-like, is a suitable basis for production of porous, ultralow weight coatings.

For coating production, FD varied between $40 \mathrm{~mm}$ and $100 \mathrm{~mm}$ and the SD varied between $250 \mathrm{~mm}$ and $350 \mathrm{~mm}$. A combination of FD $100 \mathrm{~mm}$ and SD $250 \mathrm{~mm}$ was used as well, not based on the previously described optimization but
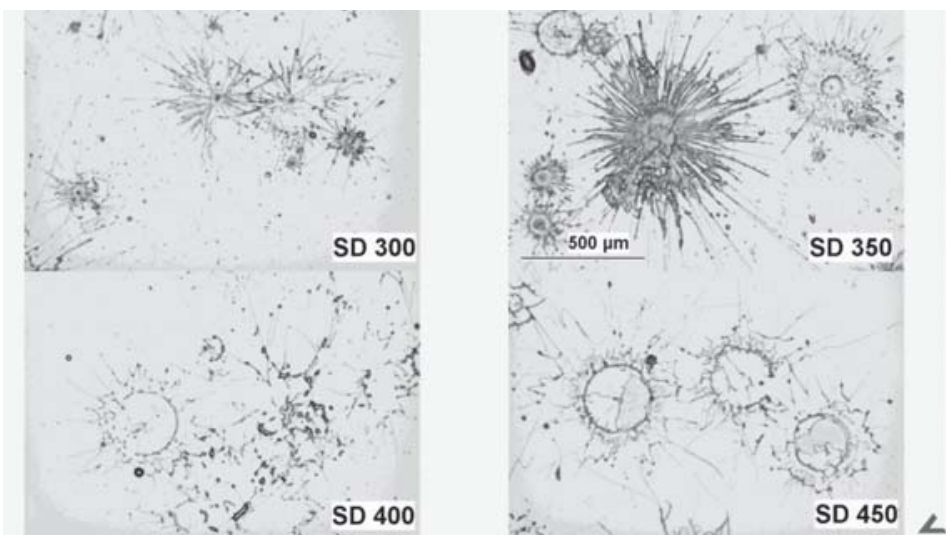

Figure 1-Splats on glass sprayed at a constant feeding distance of $40 \mathrm{~mm}$

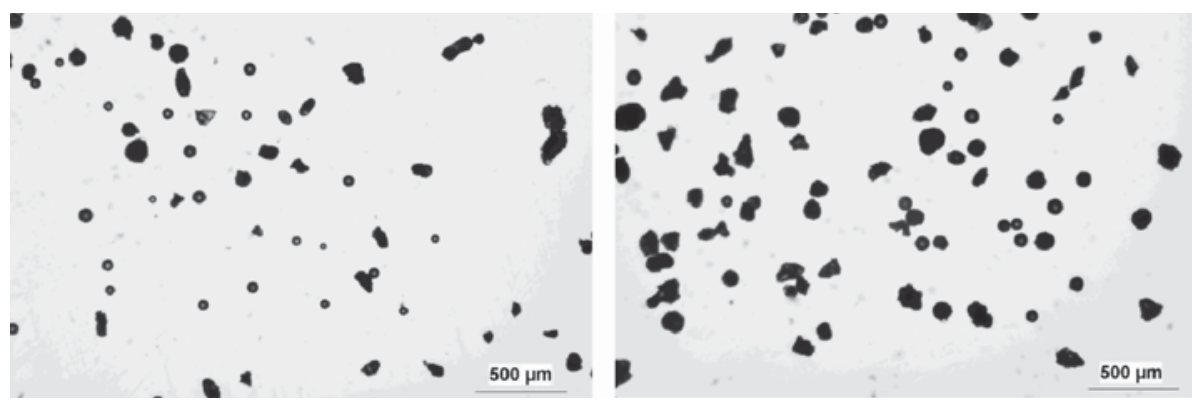

Figure 2-Free-flight particles collected at feeding distances $40 \mathrm{~mm}$ (left) and $80 \mathrm{~mm}$ (right), optical micrograph 


\section{Natural tourmaline as an efficient alternative to ceramic-type material for plasma spraying}

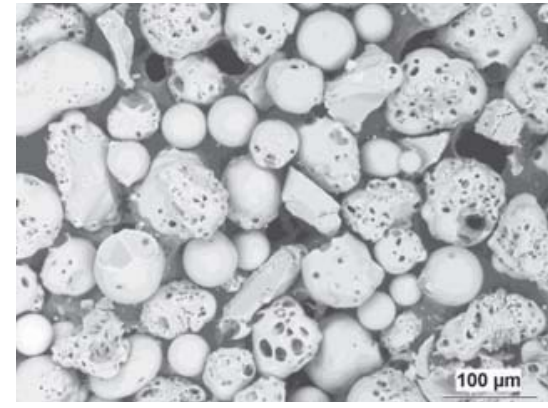

Figure 3-Free-flight particles collected at a feeding distance of $40 \mathrm{~mm}$, SEM-BSE image

in order to minimize the trajectory length where the hot powder is surrounded by reactive air.

A representative microstructure of as-sprayed tourmaline cross-section is shown in Figure 4. A lamellar structure, typical for plasma sprayed coatings, is suppressed by a large amount of pores and unmelted or prematurely re-solidified particles in the coating. Multiple cracks and predominantly globular pores were also observed.

The porosity (Table I) as measured by IA was lower for FD40/SD350 coating and extremely high for FD90/SD250 coating. The equivalent diameter (ED, i.e. mean size) of pores for the second coating was about 15 times smaller than the maximum. The number of pores per square millimeter was only 670, whereas for other coatings from natural mineral feedstock it was typically much higher (Table I). This means that tourmaline pores are large and, compared to olivines (Ctibor et al., 2015a), not very frequent. The specific weight determined by Archimedes' principle was higher for the FD40/SD350 coating and lower for the FD90/SD250 coating.

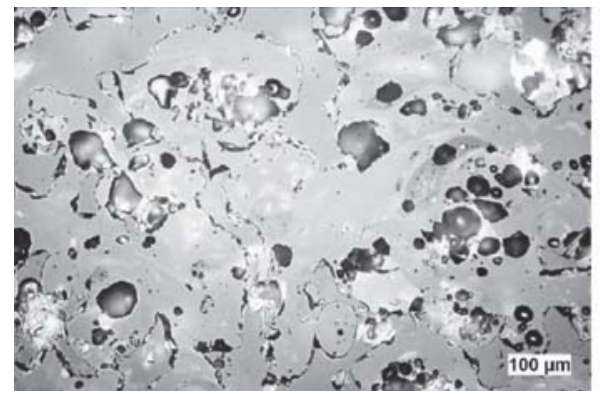

The specific weight is always markedly lower than for tourmaline mineral.

The wear resistance for the 'low porosity' coating FD40/SD350 was much lower than for other sprayed silicates such as basalt or garnet (Table I).

The phases present were quantified by Rietveld analysis of the XRD patterns of the feedstock powder. The powder was composed of $97.2 \%$ tourmaline, $1.3 \%$ rutile $\left(\mathrm{TiO}_{2}\right)$, and $1.5 \%$ phlogopite - a brown mica with chemical formula $\mathrm{KMg}_{3}\left(\mathrm{Si}_{3} \mathrm{Al}\right) \mathrm{O}_{10}(\mathrm{OH}, \mathrm{F})_{2}$. As opposed to the feedstock powder, which was fully crystalline, the material after spraying was partly amorphous (a halo located between $18^{\circ}$ and $38^{\circ} 2 \theta$ in the XRD pattern) with the crystalline phase content varying depending on the FD/SD combination (Figure 5 ). The crystalline part of the material exhibited one phase only - tourmaline.

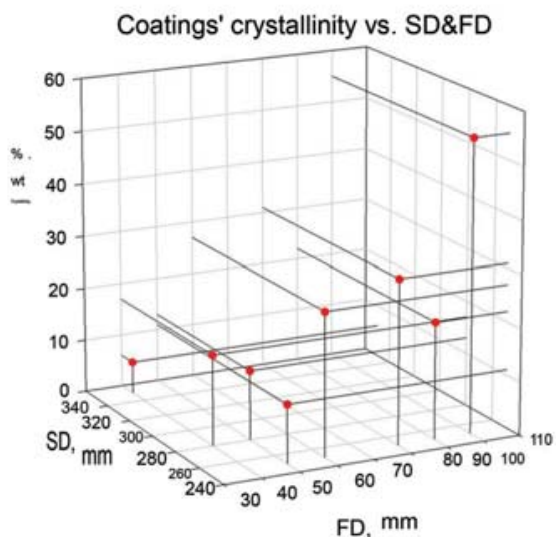

Figure 5-Crystallinity of tourmaline coatings at varying FD and SD

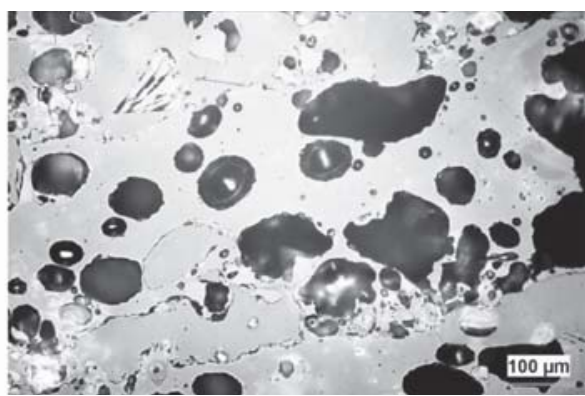

Figure 4-Coatings sprayed using FD $40 \mathrm{~mm}$ with SD $350 \mathrm{~mm}$ (left), and FD $90 \mathrm{~mm}$ with SD $250 \mathrm{~mm}$ (right)

Table I

\section{Characteristics of selected tourmaline coatings with comparison to other silicates}

\begin{tabular}{|c|c|c|c|c|c|}
\hline Plasma sprayed & $\begin{array}{c}\text { Porosity } \\
\text { (image analysis) (\%) }\end{array}$ & $\begin{array}{c}\text { Equivalent diameter ( } \mu \mathrm{m}) \\
\text { mean (maximum) }\end{array}$ & $\begin{array}{l}\text { Number of objects } \\
\text { per } \mathrm{mm}^{2}\end{array}$ & $\begin{array}{c}\text { Specific weight } \\
\text { (g.cm-3) }\end{array}$ & $\begin{array}{c}\text { Wear resistance, inverse } \\
\text { wear rate }\left(\mathrm{m} . \mathrm{mm}^{-3}\right)\end{array}$ \\
\hline Tourmaline FD40/SD350 & $16 \pm 3$ & $8.7 \pm 0.6$ & 1145 & 1.67 & 14.7 \\
\hline $\begin{array}{l}\text { Tourmaline } \\
\text { FD90/SD250 }\end{array}$ & $44 \pm 8$ & $\begin{array}{l}10.5 \pm 1.0 \\
(149 \pm 27)\end{array}$ & 670 & 1.18 & n.a. \\
\hline Olivine & 14 & 7.3 & $990-1170$ & n.a. & 63 \\
\hline Garnet & n.a. & n.a. & n.a. & n.a. & 45 \\
\hline Basalt & n.a. & n.a. & n.a. & n.a. & $38-42$ \\
\hline
\end{tabular}




\section{Natural tourmaline as an efficient alternative to ceramic-type material for plasma spraying}

In general, the longer the FD and the shorter the SD, the greater the degree of crystallinity. This verified that the combination of long FD and short SD used to minimize the trajectory length where the dwell time in a molten state is minimized was an efficient way of obtaining a predominantly crystalline coating.

The surface roughness parameter $R a$ is displayed in Figure 6 . The values between $20 \mu \mathrm{m}$ and $40 \mu \mathrm{m}$ are comparable with e.g. WSP (a similar spray technique to WSP$\mathrm{H}$ ) sprayed $\mathrm{TiO}_{2}$ (Ctibor, Sedlacek, and Pala, 2016) or WSPsprayed Ce:YAG (Ctibor et al., 2014), and slightly lower than WSP-sprayed natural diopside (Ctibor et al., 2015b). For low SD the roughness increases with higher FD. A combination of FD 100 with SD 250 yielded the highest roughness. This is an indication of slowly impacting particles. Crystallinity of the sample FD100/SD250 was the highest, therefore the slow impact led to longer cooling and to crystallization at nonovercooling conditions.

Chemical resistance was tested by immersing a piece of plasma-sprayed SSP (sample FD60/SD250) in nitric acid. A commercial $65 \%$ solution of $\mathrm{HNO}_{3}$ in water was used and the duration of the test was 100 hours. The low specific weight of the sprayed tourmaline (less than $1.5 \mathrm{~g} . \mathrm{cm}^{-3}$ ) resulted in its floating on the acid surface. However, after 18 hours it started to sink and at the end of the test it was lying on the base of the flask. This indicates certain chemical changes, most probably leaching.

The initial crystallinity of this sample, about $27 \%$ (Figure 5), decreased after leaching to $14.5 \%$. However, the diffraction pattern corresponded strictly to tourmaline. Also, the amorphous fraction of the material was preferentially leached, which led to an increase in specific weight since the crystalline material was commonly heavier.

XRD phase analysis of the sample annealed for 8 hours revealed the presence of boromullite $\left(\mathrm{Al}_{9} \mathrm{BSi}_{2} \mathrm{O}_{19}\right)$ and haematite $\left(\mathrm{Fe}_{2} \mathrm{O}_{3}\right)$. On annealing, $\mathrm{Na}, \mathrm{F}$, and $\mathrm{OH}$ groups were released from the original tourmaline $\left(\mathrm{NaFe}_{3} \mathrm{Al}_{6}\left(\mathrm{BO}_{3}\right)_{3} \mathrm{Si}_{6} \mathrm{O}_{18}(\mathrm{OH}, \mathrm{F})_{4}\right)$ phase. Incorporation of boron into the mullite-like phase was reported by Henderson (1971). The other elements were incorporated in new phases. The transformation temperature of the original tourmaline powder was revealed by an endothermic peak on the DTA curve with onset at $890^{\circ} \mathrm{C}$ (Figure 7), which is in good agreement with values in the literature (Henderson, 1971):

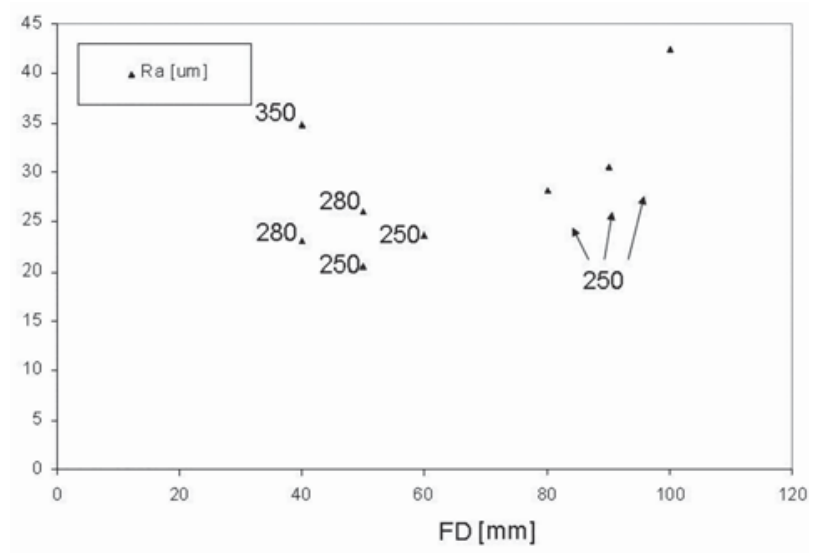

Figure 6-Surface roughness of plasma-sprayed tourmaline. Corresponding SD $(\mathrm{mm})$ indicated at each point
$880 \pm 10^{\circ} \mathrm{C}$

Reflectance results are displayed in Figure 8. Surfaces of the as-sprayed and annealed (30 minutes) FD40/SD350 and FD100/SD250 coatings were compared in a wavelength range $250 \mathrm{~nm}$ to $2000 \mathrm{~nm}$. Local maxima at about $1450 \mathrm{~nm}$ and $1950 \mathrm{~nm}$ were attributed to adsorbed water (ambient moisture) and were present in all materials. The flat region between $830 \mathrm{~nm}$ and $1000 \mathrm{~nm}$ is an instrumental artifact. The FD40/SD350 coating had a reflectance about 10\% (of that of the $\mathrm{BaSO}_{4}$ standard) through most of the observed wavelength range. After annealing, the reflectance partly increased in the range below $1450 \mathrm{~nm}$. In this range it was similar to the as-sprayed FD100/SD250 coating. The F100/SD250 coating was markedly changed by annealing. In the whole visible band and mainly in the infrared band, the reflectivity increased markedly to about $30 \%$. This corresponds with its reddish colour (Figure 9), which is caused by haematite.

After annealing, the microstructure was almost unchanged (Figure 10). After 30 minutes the coating on a ceramic tile (left) was still porous and the extremely large pores tended to cluster together. After 8 hours the SSP tended to show pore clustering and reorientation into lines parallel with the former substrate. This sample would very likely delaminate when exposed to long-term heating.

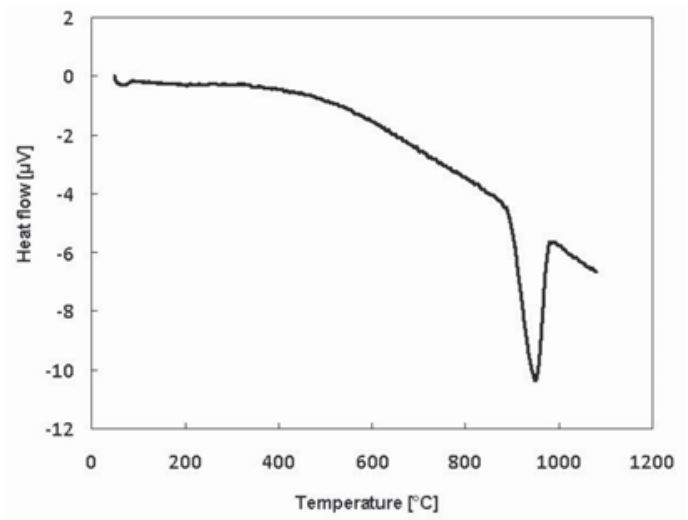

Figure 7-DTA curve of tourmaline feedstock powder

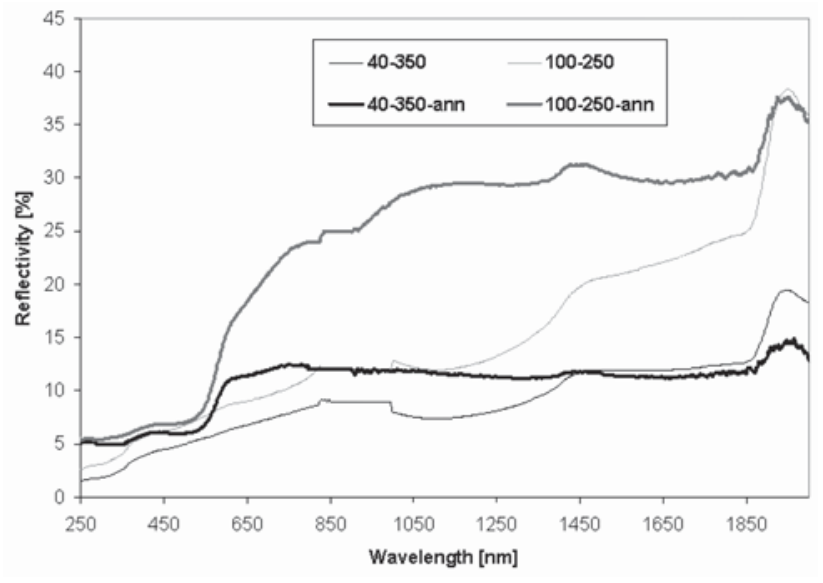

Figure 8-Reflectance of tourmaline coatings with varying FD and SD 


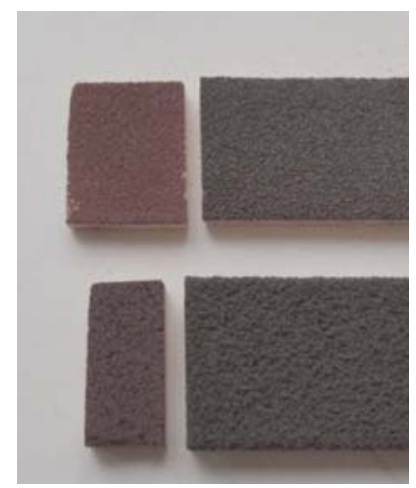

Figure 9-Colour changes of tourmaline coatings - annealed coatings are on the left. Top: FD100/SD250; bottom: FD40/SD350
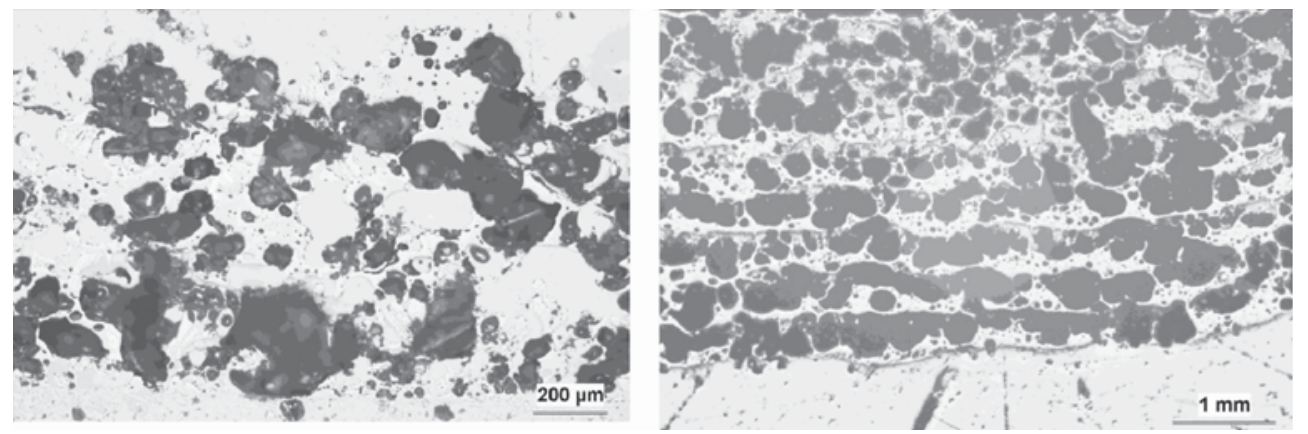

Figure 10-Micrographs of cross-sections of annealed samples. A coating after $1000^{\circ} \mathrm{C}$ for 30 minutes (left) and a SSP after $1000^{\circ} \mathrm{C}$ for 8 hours (right)

The microhardness increased markedly with annealing (Table II). This is due to the formation of new phases, namely boromullite. A hardness value for boromullite could not be found, but mullite has a Vickers microhardness up to $15 \mathrm{GPa}$ (Shackelford and Doremus, 2008).

\section{Conclusions}

Tourmaline is an inexpensive natural material that can be successfully processed by the plasma spray technique to form self-supporting plates stripped from steel substrates or coatings on metallic and ceramic substrates. This study demonstrated this ability using a novel hybrid water-argon stabilized plasma spray system WSP-H. Despite the disordered structural character (phase composition containing chemically bonded water, incongruent melting, as well as microstructural homogeneity), plasma-deposited tourmaline exhibited relatively good chemical resistance in nitric acid $\left(65 \% \mathrm{HNO}_{3}\right.$ in water). The porosity of the deposits was very high and the material was partly amorphous after spraying, with the crystallinity being dependent on a combination of feeding and spraying distances. The observed mechanical properties of the as-sprayed tourmaline are due to its high porosity. Therefore, tourmaline is not fully comparable with other silicates. In particular, the wear resistance of tourmaline was low. Microstructural modification by annealing, i.e. crystallization into phases without $\mathrm{OH}$ groups, appeared to be not favourable in terms of defect healing, probably due to the incongruent melting caused also by other impurities. However, the microhardness increased markedly because of the formation of new harder phases.

\begin{tabular}{|c|c|}
\hline \multicolumn{2}{|c|}{$\begin{array}{l}\text { Table /I } \\
\text { Microhardness characteristics }\end{array}$} \\
\hline Sample & Microhardness [GPa] \\
\hline $\begin{array}{l}\text { FD40/SD350 } \\
\text { FD90/SD250 } \\
\text { Annealed } 30 \text { min, FD90/SD250 } \\
\text { Annealed } 8 \text { h, FD90/SD250 }\end{array}$ & $\begin{array}{c}8.7 \pm 1.4 \\
9.3 \pm 0.9 \\
12.7 \pm 1.2 \\
13.5 \pm 1.6\end{array}$ \\
\hline
\end{tabular}

\section{Acknowledgments}

This work was supported by MSMT (Ministry of Education, Youth and Sports) programme NPU I, project no. L01207. The authors wish to thank Mr Jan Soumar, who assisted in the proofreading of the technical English of the manuscript.

\section{References}

ASTM. 1995. ASTM G 75-95: Standard test method for determination of slurry abrasivity (Miller number) and slurry abrasion response of materials (SAR number) ASTM International, West Conshohocken, PA.

Cojocaru, C.V., Lamarre, J.-M., Legoux, J.-G., and Marple, B.R. 2013. Atmospheric plasma sprayed forsterite $\left(\mathrm{Mg}_{2} \mathrm{SiO}_{4}\right)$ coatings: An investigation of the processing -microstructure-performance relationship. Journal of Thermal Spray Technology, vol. 22, no. 2-3. pp. 145-151.

CtiBor, P., Brožek, V., and Hofman, R. 2003. Boron carbide synthesis at plasma spray process. Proceedings of the 16th International Symposium on Plasma Chemistry. d'Agostino, R., Favia, P., Fracassi, F., and Palumbo, F. (eds.). Department of Chemistry, University of Bari, Italy. p. 631.

CTibor, P., KubÁt, J., Nevrlá, B., and PalA, Z. 2014. Plasma spraying of ceriumdoped YAG. Journal of Materials Research, vol. 29, no. 19. pp. 2344-2351. 


\section{Natural tourmaline as an efficient alternative to ceramic-type material for plasma spraying}

Ctibor, P., Neufuss, K., Pala, Z., Kotlan, J., and Soumar, J. 2015a. Dielectric and mechanical properties of plasma-sprayed olivine. Romanian Reports in Physics, vol. 67, no. 2. pp. 600-616.

Ctibor, P., Nevrlá, B., Pala, Z., Sedláček, J., Soumar, J., Kubatík, T., Neufuss, K., VilÉMOVÁ, M., and MEDŘicKÝ, J. 2015b. Study on the plasma sprayed amorphous diopside and annealed fine-grained crystalline diopside. Ceramics International, vol. 41, no. 9. pp. 10578-10586.

CTiBor, P., SEDlaceK, J., and PALA, Z. 2016. Dielectric and electrochemical properties through-thickness mapping on extremely thick plasma sprayed $\mathrm{TiO}_{2}$. Ceramics International, vol. 42, no. 6. pp. 7183-7191.

Fauchais, P., Fukumoto, M., Vardelle, A., and Vardelle, M. 2004. Knowledge concerning splat formation: An invited review. Journal of Thermal Spray Technology, vol. 13, no. 3. pp. 337-360.

HAWKins, K.D., MAcKinnon, D.R., and ScHNEEBERGER, H. 1995. Influence of chemistry on the pyroelectric effect in tourmaline. American Mineralogist, vol. 80, no. 5-6. pp. 491-501.

Henderson, E. 1971. Chemical and physical properties of tourmaline. PhD thesis, Plymouth Polytechnic, UK.

Jenista, J., Takana, H., Nishiyama, H., Bartlova, M., Aubrecht, V., Krenek, P. Hrabovsky, M., Kavka, T., Sember, V., and Maslani, A. 2011. Integrated parametric study of a hybrid-stabilized argon-water arc under subsonic, transonic and supersonic plasma flow regimes. Journal of Physics D: Applied Physics, vol. 44 no. 43. pp. 1-20.

LIU, S.M., LI, D.C., Hu, W.T., QIN, G.Q., and LI, L.F. 2008. Ion-beam deposition of tourmaline film on glass. Journal of Non-Crystalline Solids, vol. 354 no. 4. pp. 1444-1446.

Rykalin, N.N. and Kudinov, V.V. 1976. Plasma spraying. Pure and Applied Chemistry, vol. 48, no. 2. pp. 229-239.

Salimijazi, H., Hosseini, M., Mostaghimi, J., Pershin, L., Coyle, T.W., SAmadi, H., and SHAFyer, A. 2012. Plasma sprayed coating using mullite and mixed alumina/silica powders. Journal of Thermal Spray Technology, vol. 21, no. 5. pp. 825-830.

SHACKELFoRD, J.F. and DoREmus, R.H. 2008. Ceramic and Glass Materials: Structure, Properties and Processing. Springer, New York. p. 37.

Wang, W., Liang, J., Guo, X., Xuan, F., and Hong, H. 2012. Mechanical properties and dissolution behavior of plasma sprayed wollastonite coatings deposited at different substrate temperatures. Journal of Thermal Spray Technology, vol. 21, no. 3-4 pp. 496-504.

Xu, H.-Y., Prasad, M., He, X.-L., Shan, L.-W., and QI, S.-Y. 2009. Discoloration of Rhodamine B dyeing wastewater by schorl-catalyzed Fenton-like reaction. Science in China, Series E Technological Sciences, vol. 52, no. 10 pp. 3054-3060.

Xu, H.-Y., PRASAD, M., and LiU, Y. 2009. Schorl: A novel catalyst in mineralcatalyzed Fenton-like system for dyeing wastewater discoloration. Journal of Hazardous Materials, vol. 165, no. 1-3 pp. 1186-1192.

Zhang, J., Zhou, Y., Peng, B., Xie, Z., Zhang, X., and Yue, Z. 2014. Microwave dielectric properties and thermally stimulated depolarization currents of $\mathrm{MgF}_{2}$-doped diopside ceramics. Journal of the American Ceramic Society, vol. 97 , no. 11 pp. 3537-3543. 